\title{
EVOLUÇÃO PAISAGÍSTICA DO USO DA TERRA DE UMA MICROBACIA ATRAVÉS DO SIG - IDRISI, NO PERÍODO DE 6 ANOS
}

\author{
Sérgio Campos ${ }^{1}$ \\ Natália Sousa Ceragioli ${ }^{2}$ \\ Mariana Wagner de Toledo Piza $^{3}$ \\ Teresa Cristina Tarlé Pissarra ${ }^{4}$ \\ Flávia Mazzer Rodrigues 5
}

RESUMO: O planejamento do uso da terra vem se tornando cada vez mais uma importante atividade para os meios rural e urbano. Nesse sentido, o uso adequado da terra, de maneira a protegê-la contra a erosão e visando aumentar gradativamente a sua capacidade produtiva, requer sempre um planejamento inicial, efetivo e eficiente. Este trabalho objetivou analisar a evolução paisagística de uma microbacia do Alto Capivara Botucatu (SP) através do uso do Sistema de Informações Geográficas - Idrisi, de imagens de satélite digital do sensor TM do LANDSAT 5, passagem de 23/10/2006, escala 1:50000 e fotografias aéreas verticais coloridas de 2000, escala 1:30000. A área com 4551,19ha está situada entre as coordenadas geográficas $22^{\circ} 51^{\prime} 57^{\prime \prime}$ a $22^{\circ} 57^{\prime} 55^{\prime \prime}$ de longitude S e de $48^{\circ} 21^{\prime} 58^{\prime \prime}$ a $48^{\circ} 26^{\prime} 38^{\prime \prime}$ de longitude WGr. Os resultados permitiram constatar que a área vem sendo ambientalmente preservada, pois se apresenta coberta com mais de

\footnotetext{
${ }^{1}$ Prof. Adjunto, Departamento de Engenharia Rural, Faculdade de Ciências Agronômicas/UNESP. seca@fca.unesp.br.

${ }^{2}$ Discente do Curso de Graduação em Agronomia da Faculdade de Ciências Agronômicas/UNESP. mcesoares@fca.unesp.br

${ }^{3}$ Discentes do Programa de Pós-Graduação em Agronomia - Energia na Agricultura da Faculdade de Ciências Agronômicas/UNESP. seca@fca.unesp.br

${ }^{4}$ Profa. Dra., Departamento de Engenharia Rural, Faculdade de Ciências Agrárias e Veterinárias/UNESP. teresapa@fcav.unesp.br.

${ }^{5}$ Discente do Programa de Graduação em Agronomia - Ciência do Solo da Faculdade de Ciências Agrárias e Veterinárias/UNESP. teresap@fcav.unesp.br
} 
20\%, mínimo exigido pela Legislação Brasileira. A alta concentração de florestas nativas e pastagens $(75,26 \%)$ é reflexo da presença de solos de baixa fertilidade na área.

Palavras-chaves: ocupação do solo, imagem Landsat e Geoprocessamento

\section{INTRODUÇÃO}

No Brasil os cursos d'água vêm sofrendo constante e crescente contaminação, por causa da utilização e preservação inadequada dos recursos naturais existentes ao redor da microbacia hidrográfica. Freqüentemente, essas águas transportam solos decorrentes de águas de chuvas que pode ter sido adubados e corrigidos a custos altíssimos, podendo reduzir a disponibilidade para irrigação e para o abastecimento. Para modificar esse cenário é importante que seja feito um planejamento para utilização racional e manejo dos recursos naturais. A microbacia é a unidade geográfica ideal para esse planejamento integrado do manejo dos recursos naturais no ecossistema (Brasil,1987).

O mapeamento desta permite estudos e planejamentos de atividades urbanas e rurais, com determinação do uso e ocupação do solo, indicação de áreas propícias à exploração agrícola, pecuária ou florestal, previsão de safras e planejamento urbano, sendo importante para o conhecimento da realidade e buscando sua recuperação quando necessária.

As imagens permitem calcular com maior precisão as áreas de lavouras, matas e pastagens, além de se constituírem um valioso instrumento para a seleção de locais para plantio de culturas anuais, formação de pomares, locação de estradas, represas, entre outros. Diferem das aerofotos por serem digitais, passíveis de processamento em computadores, não apresentam distorções radiais e são compostas por bandas, que permitem a recombinação de cores.

A alta resolução espacial, espectral e temporal dos atuais sistemas de sensores permite que com o uso de aplicativos de computador, para o tratamento e processamento das imagens, obtenham-se análises precisas de qualquer fenômeno que esteja ocorrendo na superfície, no interior da terra e dos mares, em um espaço de tempo curto e com a possibilidade de acompanhamento da evolução destes fenômenos. 
Este trabalho de pesquisa avaliou o uso da terra da microbacia do Alto Capivara Botucatu (SP) obtida através de imagem de satélite e de fotografias aéreas verticais coloridas.

\section{MATERIAL E MÉTODOS}

O trabalho foi desenvolvido numa microbacia do Alto Capivara - Botucatu (SP), situada geograficamente entre as coordenadas geográficas: latitude $22^{\circ} 51^{\prime} 57^{\prime \prime}$ a $22^{\circ} 57^{\prime}$ $55^{\prime \prime}$ S e longitudes $48^{\circ} 21^{\prime} 28^{\prime \prime}$ a $48^{\circ} 26^{\prime} 38^{\prime \prime}$ WGr., com uma área de 4551,19ha.

Utilizaram-se fotografias aéreas verticais coloridas, em escala nominal aproximada de 1:30000 (2000), para elaboração do mapa da ocupação do solo de 2000, tendo-se como referência planimétrica para restituição aerofotogramétrica a Carta do Brasil em escala 1:50000 (1969), editada pelo IBGE, referentes ao município de Botucatu.

$\mathrm{Na}$ observação estereoscópica e transferência dos elementos das fotografias aéreas foram utilizadas, respectivamente, o estereoscópio de espelhos WILD, modelo ST-4 e o aerosketchmaster Carl Zeiss, Jena.

Para identificar as coberturas vegetais seguiu-se os critérios gerais de fotogrametria e de fotointerpretação agrícola descritos por Ricci \& Petri (1965), Marchetti \& Garcia (1977) e Piedade (1983).

As áreas de cobertura vegetal em 2000 foram obtidas através de fotografias aéreas verticais coloridas, escala 1: 30000 e de 2006 da imagem de satélite digital do sensor TM do LANDSAT 5, passagem de 23/10/2006, escala 1:50000, utilizando-se de combinações das bandas 3, 4 e 5, pois esta apresenta uma boa discriminação visual dos objetos de interesse, possibilitando a identificação dos padrões de uso da terra de maneira lógica. Uma vez que esta composição apresenta os corpos d'água em tons azulados, as florestas e outras formas de vegetações em tons esverdeados e os solos expostos em tons avermelhados.

Em seguida, fez-se o georreferenciamento da composição falsa cor, utilizando-se o módulo Reformat/Resample do SIG - IDRISI, sendo os pontos de controle obtido nas cartas planialtimétricas do Instituto Brasileiro de Geografia e Estatística - IBGE, em escala 1:50000, referente ao Município de Botucatu (SF-22-R-IV-3), editada em 1969. 
No georreferenciamento utilizou-se dois arquivos de pontos de controle, sendo o primeiro da imagem digital e o outro, da carta topográfica de Botucatu. Foram determinadas as coordenadas de cada ponto e com estes dados foi feito um arquivo de correspondência, através do comando "Edit" do menu "Database Query", presente no módulo "Analysis".

Após o georreferenciamento foi feita a delimitação da imagem, extraindo-se apenas a área da microbacia, sendo posteriormente demarcadas as áreas de treinamento sobre a imagem com o cursor e o mouse. Essas áreas foram demarcadas, buscando-se abranger todas as variações de cada ocupação do solo. Depois, foram delimitados polígonos desenhados, utilizando a interpretação em tela, as ocupações do solo foram identificadas e diferenciadas umas das outras, pelas respostas espectrais. Esse tipo de classificação procura reconhecer áreas homogêneas baseadas nas propriedades espectrais e espaciais de imagens. A informação da borda é utilizada para separar áreas de mesma textura, sendo considerado um método subjetivo, já que em pequenas áreas de vegetação, os critérios dependem da experiência do observador. Em seguida, foram indicados os nomes para cada classe de uso da terra, associados aos seus respectivos identificadores, sendo a imagem classificada e os cartogramas demonstrativos da distribuição espacial de cada uso da terra com base nestes dados.

Na identificação digital dos alvos utilizou-se as chaves de interpretação para imagens (Rocha, 1986) na determinação das 6 classes de uso: reflorestamento, uso agrícola, pastagem, floresta nativa, solo exposto e outros.

As áreas foram medidas com o auxílio do SIG - IDRISI utilizando-se do comando "Area" do menu "Database Query", pertencente ao módulo "Analysis".

\section{RESULTADOS E DISCUSSAO}

A análise da imagem digital referente à passagem de 8/06/97 em composição colorida nas bandas TM3,TM4 e TM5 do Landsat 5 através do Sistema de Informação Geográfica (SIG) - IDRISI permitiu discriminar, mapear e quantificar sete feições através da classificação supervisionada na bacia em estudo: reflorestamento, mata composta, várzea, pastagem, mata ciliar, cultura e estrada da terra: reflorestamento, floresta, 


\section{Periódica Eletrônica

pastagem, uso agrícola, solo exposto e outros (Figuras 1 e 2).

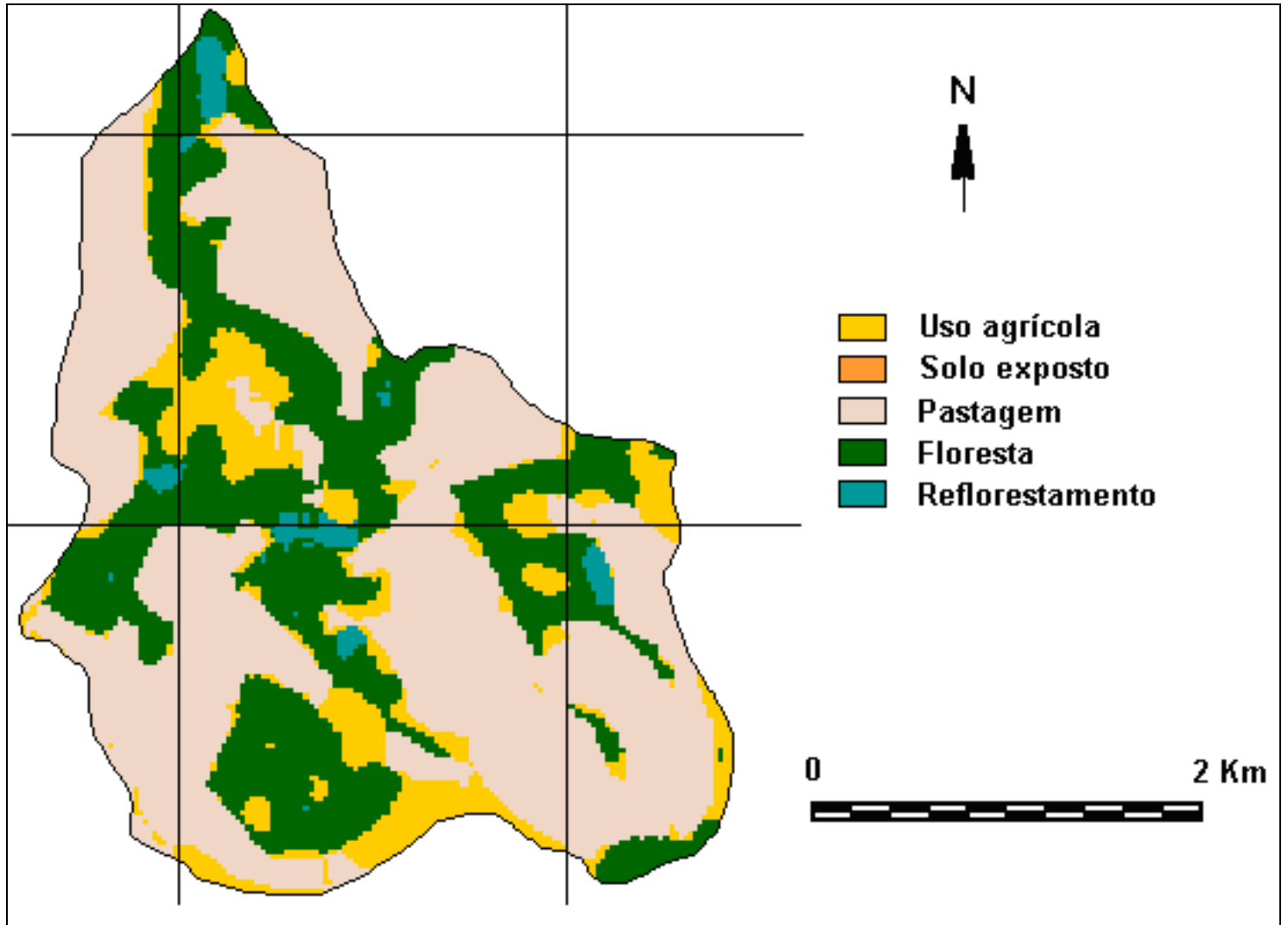

Figura 1. Uso da terra da microbacia do Alto Capivara - Botucatu (SP) em 2000

A análise do uso da terra da microbacia do Alto Capivara - Botucatu (SP) através das Figuras 1 e 2 e da Tabela 1 mostra que as pastagens (54,8\%) e os reflorestamentos $(10,72 \%)$ vêm predominando em 2/3 (523,96ha), mostrando assim o domínio do reflorestamento e da pecuária na região, reflexo da predominância de solos de baixa fertilidade, conforme Barros (1990) e Campos (1997). 


\section{Periódica Eletronica

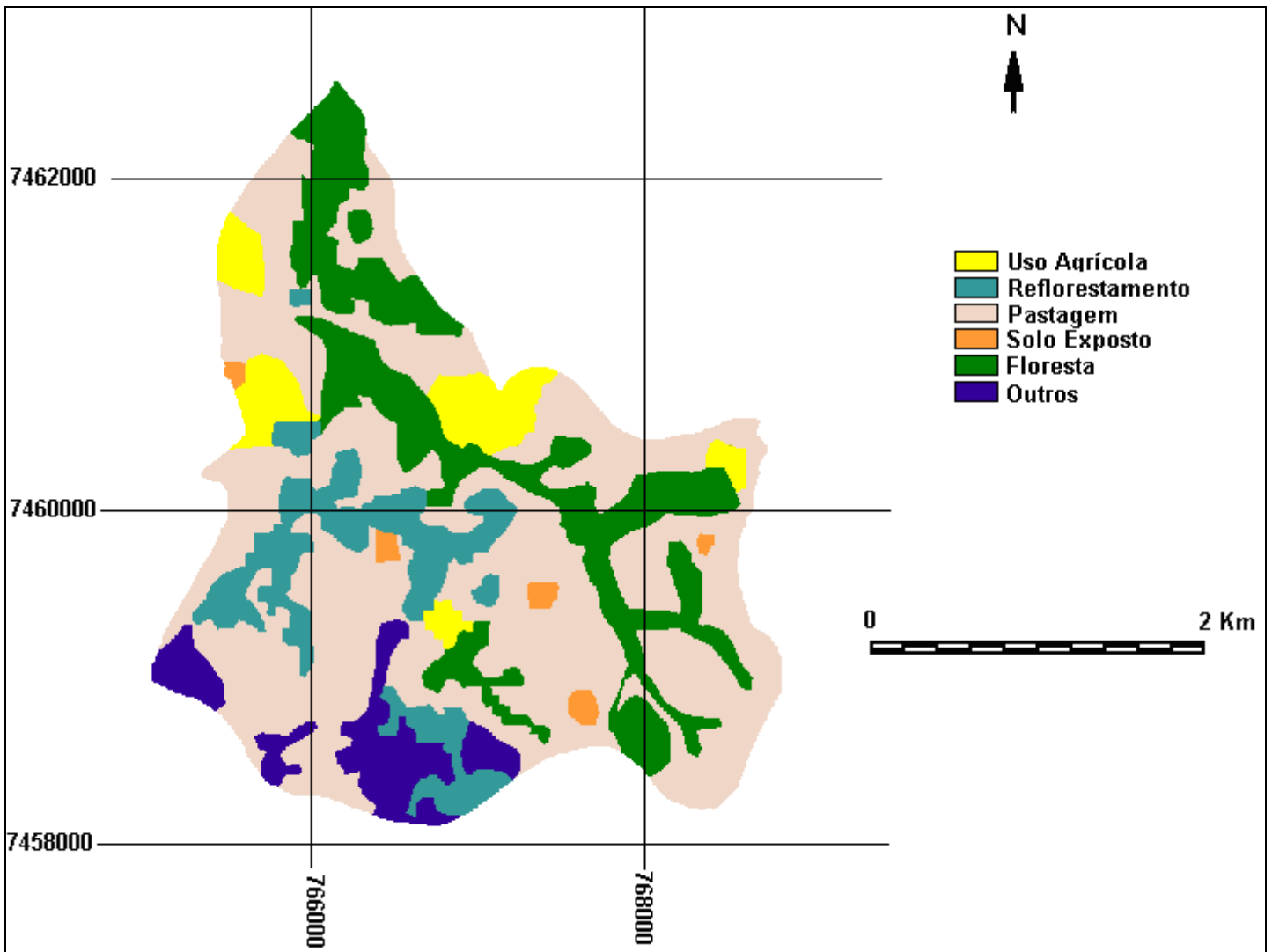

Figura 2. Uso da terra da microbacia na bacia do Alto Capivara - Botucatu (SP) em 2006

Tabela 1. Uso da terra da microbacia do Alto Capivara - Botucatu (SP) no período de 6 anos

\begin{tabular}{cccccc}
\hline \multirow{2}{*}{ Uso da terra } & \multicolumn{2}{c}{2000} & \multicolumn{4}{c}{ Área da microbacia } & \multicolumn{2}{c}{2006} & \% de redução \\
& ha & $\%$ & Ha & $\%$ & e amnliacão \\
\hline Uso Agrícola & 127,13 & 13,30 & 62,99 & 6,59 & $50,45(\mathrm{R})$ \\
Reflorestamento & 19,75 & 2,06 & 102,52 & 10,72 & $419(\mathrm{~A})$ \\
Pastagens & 517,38 & 54,12 & 523,96 & 54,80 & $1,27(\mathrm{~A})$ \\
Solo exposto & 0,00 & 0,00 & 10,66 & 1,12 & $100(\mathrm{~A})$ \\
Floresta & 291,81 & 30,52 & 195,59 & 20,46 & $32,97(\mathrm{R})$ \\
Outros & 0,00 & 0,00 & 60,35 & 6,31 & $100(\mathrm{~A})$ \\
\hline
\end{tabular}

Cardoso comprovou em 1988 que a cobertura do solo por reflorestamento foi 
eficiente na proteção da rede de drenagem em regiões com processos erosivos. Nesse sentido, Coelho (1968) já afirmava que como as derrubadas de matas naturais não são impedidas e sua regeneração é lenta, a eucaliptocultura atende não só as necessidades econômicas, como se constitui numa forma de proteção contra o processo erosivo, pois para Vieira (1978), essa cobertura vegetal tem grande influência nos processo de escoamento, atuando no mecanismo hidrológico, retardando e desviando o escoamento superficial e conseqüentemente a erosão.

O reflorestamento para Campos (1997) deve ser cada vez mais incrementado na região como forma de proteção racional integrada da área, principalmente, porque essas atividades mostram ótimos retornos econômicos para a região.

A área vem sendo ambientalmente preservada, pois se apresenta com uma cobertura com $20,46 \%$ de floresta. O reflorestamento foi uma atividade crescente, apresentando uma grande ampliação de $419 \%$, ou seja, passou no período de 19,75 ha (2000) para 102,52ha (2006), porém o uso agrícola apresentou um decréscimo de 50,45\%, ou seja, passando em de 19,75ha para 102,52ha em 2006.

As florestas nativas e as pastagens cobrindo mais de $75 \%$ da área abrangida pela microbacia, reflem a predominância de solos de baixa fertilidade, conforme Barros (1990) e Campos (1993). O Código Florestal Brasileiro (1965) determina que a reserva mínima de florestas deva ser de $20 \%$. Este é um parâmetro muito importante, pois de acordo com Rocha (1991), as florestas são fundamentais no controle de erosão e de enchentes, pois quando situadas em locais adequados são fundamentais na recarga do lençol freático. As transformações na cobertura vegetal acontecem de forma dinâmica na microbacia, ao longo do tempo, com a região sofrendo mudanças nas paisagens nesses últimos 6 anos, caracterizadas principalmente pela expansão da silvicultura.

O dimensionamento de áreas através de dados do Sensoriamento Remoto, principalmente pelas imagens de satélite, é muito viável por permitir a identificação, o mapeamento e a quantificação dos recursos naturais renováveis a cada 16 dias, contribuindo também para o fato de possibilitar o "mapeamento" em grandes áreas e em curto espaço de tempo.

O SIG - IDRISI foi muito importante no tratamento dos dados para a obtenção do mapeamento, permitindo a sua obtenção mais rápida. A etapa que mais demandou 
tempo foi a obtenção de dados a campo (verdade terrestre).

O reflorestamento apesar de ser a segunda cobertura em área, é uma cobertura vegetal que apresenta uma tendência de evolução, uma vez que na região existem grandes Companhias Reflorestadoras que vieram para essa região em busca de terras menos valorizadas e com potencialidades para essências florestais (Barros,1988) e que de acordo com Coelho (1968), essas populações com Eucalipto atendem as necessidades econômicas e constituem-se numa forma de proteção contra o processo erosivo do solo, pois o solo não ficando exposto a ação das chuvas, conseqüentemente as erosões deixarão de aparecer e nem os elementos nutritivos essenciais para a sobrevivência das serão lixiviados.

As matas, as quais são constituídas por tipos de vegetações arbóreas, como florestas nativas primárias e secundárias e matas de galeria, vem se tornando cada vez mais escassa na região, sendo estas ocupadas por pastagens.

O Sistema de Informação Geográfica foi eficiente na identificação, mapeamento e na determinação dos usos da terra, conforme já havia constatado Ribeiro (1998), minimizou a complexidade e o grau de subjetividade na determinação das áreas ocorridas a partir dos cruzamentos realizados manualmente (Assad et al., 1993), permitindo mais rapidamente a combinação de várias informações através do algorítmo de manipulação gerando novos mapeamentos, segundo Câmara (1993).

\section{CONCLUSÃO}

As fotografias aéreas verticais coloridas permitiram o mapeamento do uso da terra da microbacia de maneira confiável, servindo de base para futuros planejamentos regionais. O SIG - IDRISI, através de seus diferentes módulos para georreferenciamento, classificação digital do uso da terra e modelo matemático permitiu a discriminação dos seguintes usos da terra: reflorestamento, uso agrícola, pastagem, floresta nativa, solo exposto e outros. A classificação digital permitiu verificar que a área vem sendo ambientalmente preservada, pois não há deficiência de florestamento, visto que se apresenta coberta com mais de 20\%, mínimo exigido pelo Código Florestal Brasileiro vigente. $O$ alto índice de ocupação do solo por pastagem na microbacia $(65,52 \%)$ reflete a 
predominância da pecuária regional. A pastagem foi a cobertura vegetal que menos alterou no período estudado, quando comparada a outras coberturas vegetais, principalmente, em detrimento da ampliação da área com reflorestamento.

\section{REFERÊNCIAS BIBLIOGRÁFICAS}

Assad, E. D., Sano, E. E., Meireles, M. L., Moreira, L. Estruturação de dados geoambientais no contexto de microbacia hidrográfica. In: Assad, E. D., Sano, E. E. Sistema de Informações Geográficas: Aplicações na agricultura. Planaltina: Embrapa-CPAC, 1993.p.173-99.

Barros, Z.X. Caracterização de bacias hidrográficas no mapeamento de solos mediante o uso de análise multivariada. Botucatu: Universidade Estadual Paulista, 1988. 113p. Tese Doutorado.

BARROS, Z.X. de, PIEDADE, G.C.R., CURI, P.R. Variáveis de ocupação do solo e análise multivariada. Rev.Geogr., São Paulo, n.8/9, 1990.

BRASIL, Ministério da agricultura. Programa nacional de microbacias hidrográficas: manual operativo, Brasília,1987. 60p.

Câmara, G. Anatomia de sistemas de informações geográficas: visão atual e perspectivas de evolução. In: ASSAD, E.D., SANO, E.E. Sistema de informações geográficas: aplicações na agricultura. Planaltina: Empresa Brasileira de Pesquisa Agropecuária, 1993. cap.4, p.15-37.

Campos, S. Diagnóstico físico conservacionista da bacia do rio Lavapés - Botucatu (SP). Botucatu: Universidade Estadual Paulista, 1997. 140p. Tese Livre-Docência.

CAMPOS, S. Fotointerpretação da ocupação do solo e suas influências sobre a rede de drenagem da bacia do rio Capivara - Botucatu (SP), no período de 1962 a 1977. Botucatu: UNESP, 1993. 164p. Tese (Doutorado em Energia na Agricultura) - Faculdade de Ciências Agronômicas, Universidade Estadual Paulista, 1993.

EASTMAN, J. R. Idrisi for windows - Manual do Usuário: Introdução e Exercícios Tutoriais. Editores da versão em português, Heinrich Hasenack e Eliseu Weber. Porto Alegre, UFRGS Centro de Recursos do Idrisi, 1998. 240 p.

Cardoso, L.G. Comportamento das redes de drenagem em solos com cana-deaçúcar e com eucalipto. Botucatu: Universidade Estadual Paulista, 1988. 139 p. Tese Doutorado.

Coelho, A.G. de. Fotointerpretação da eucaliptocultura e estudo do planejamento agrícola. Campinas: Boletim do Instituto Agronômico, 1968, n.187, p.1-60. 
MARCHETTI, D.A.B., GARCIA, G.J. Princípios de fotogrametria e fotointerpretação. São Paulo: Nobel, 1977, 257p.

PIEDADE, G.C.R. Noções de fotogrametria e fotointerpretação. Faculdade de Ciências Agronômicas. 1983. 44p. (apostila).

Ribeiro, F.L. Sistemas de Informações Geográficas aplicados ao mapeamento dos usos atual e adequado da terra do Alto Rio Pardo - Botucatu (SP). Botucatu: Universidade Estadual Paulista, 1998. 140p. Dissertação Mestrado.

RICCI, M., PETRI, S. Princípios de aerofotogrametria e interpretação geológica. São Paulo: Cia Editora Nacional, 1965. 226p.

ROCHA, J.S.M. da. Manual de interpretação de aerofotogramas. Fascículo XI, Santa Maria, 1986, 58p.

ROCHA, J.S. M. da., Manual de manejo integrado de bacias hidrográficas. ed. UFSM, Santa Maria, RS. 1991. 181p.

Vieira, N.M. Estudo geomorfológico das voçorocas de Franca, SP. Franca: Universidade Estadual Paulista, 1978. 255p. Tese Doutorado. 